\title{
Efeito da densidade populacional e época de colheita na produção de raízes de mandioca de mesa
}

\author{
Eduardo Barreto Aguiar $\left({ }^{(*)}\right)$; Teresa Losada Valle ('); José Osmar Lorenzi ( $\left.{ }^{2}\right)$; Ricardo Augusto Dias \\ Kanthack ( $\left.{ }^{3}\right)$; Hilario Miranda Filho $\left({ }^{2}\right)$; Newton do Prado Granja $\left({ }^{2}\right)$ \\ (') Universidade Estadual Paulista (UNESP), Programa de Pós-graduação em Agricultura, Rua José Barbosa de Barros, n. 1780, \\ 18610-307 Botucatu (SP). \\ (2) Instituto Agronômico (IAC), Centro de Horticultura, Caixa Postal 28, 13012-970 Campinas (SP). \\ (3) Agência Paulista de Tecnologia dos Agronegócios (APTA), Polo Médio Paranapanema, Caixa Postal 263, $18802-970$ Assis (SP). \\ $\left({ }^{*}\right)$ Autor correspondente: aguiareb@msn.com
}

Recebido: 1.\%ut./2010; Aceito: 17/dez./2010.

\begin{abstract}
Resumo
Em cultivos tradicionais de mandioca de mesa (Manihot esculenta Crantz), bons rendimentos quanto à produção e qualidade das raízes, são obtidos a partir de oito a dez meses após o plantio. Plantas submetidas à menor competição resultam em maior produção de raízes. O objetivo deste trabalho foi avaliar a densidade populacional como instrumento para a produção precoce de raízes comerciais. O experimento foi desenvolvido no ano agrícola de 2001/2002, utilizando-se a cultivar IAC 576-70, em sete densidades populacionais variáveis de 5.000 e 20.000 plantas ha-1 ${ }^{-1}$ com colheitas aos seis, oito, dez, doze,

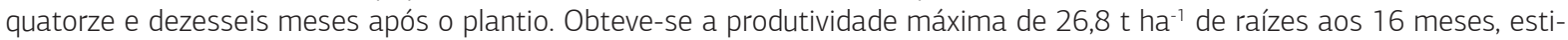
mada por regressão na densidade de 20.000 plantas ha-1 ${ }^{-1}$ No entanto, as maiores produções de raízes comerciais ocorrem nas menores densidades populacionais, para todas as épocas de colheita estudadas, devido à menor taxa de descarte de raízes que se observa nas baixas populações. Nas colheitas precoces, aos seis e oito meses, observaram-se as produções

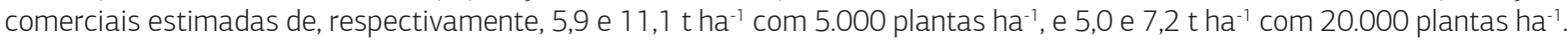
Esses resultados demonstram que, baixas densidades populacionais em mandioca de mesa possibilitam colheitas precoces, aos 6, 8 e 10 meses após o plantio, com bons rendimentos comerciais de raízes.
\end{abstract}

Palavras-chave: Espaçamento, precocidade, práticas culturais.

\section{Effect of plant densities and harvest dates on the production of sweet cassava roots}

\section{Abstract}

In sweet cassava production, economic yields of high quality roots are obtained only after a growing season of eight to ten months. In addition, cassava plants under little competition present higher yields per plant. The objective of this work was to study the handling of population densities in the sweet cassava crop, as a tool to obtain high yield of high quality roots in earlier harvests. Seven plant densities, from 5,000 to 20,000 plants ha ${ }^{-1}$, were tested with growing cycles of six, eight, ten, twelve, fourteen and sixteen months, in a field trial using the cv. IAC 576-70. Total root yields increased with time, being the highest values obtained with the highest plant densities. It was estimated, with a regression model, a maximum yield of 26.8 $\mathrm{t} \mathrm{ha}^{-1}$, when using 20,000 plants ha-1 and a growing cycle of sixteen months. On the other hand, the highest yields of marketable roots were obtained with smaller plant densities in all harvests, which was caused by lower root discard rate at low populations. The maximum yield was $19.1 \mathrm{t} \mathrm{ha}^{-1}$ in the latest harvest by using 5,000 plants. In earlier harvests, after six and eight months, the marketable yields estimated were $5.9 \mathrm{t} \mathrm{ha}^{-1}$ and $11.1 \mathrm{t} \mathrm{ha}^{-1}$, when using 5,000 plants; and $5.0 \mathrm{t} \mathrm{ha-1}$ and 7.2 t ha ${ }^{-1}$ with 20,000 plants. In this way, low population densities for the sweet cassava crop enable earlier harvests, at six, eight and ten months after planting with good yields of commercial roots.

Key words: Spacing, earliness, cultural practices. 


\section{INTRODUÇÃO}

A mandioca de mesa (Manihot esculenta Crantz) pode ser considerada como um produto hortícola amplamente consumido em todo o Brasil. Nos grandes centros urbanos é comercializada in natura, minimamente processada ou processada na forma de pré-cozidos, congelados e massas. Esse mercado está em expansão, tanto para o abastecimento interno como para exportação, todavia devido à deterioração pós-colheita, exige abastecimento contínuo.

Nas raízes de mandioca com boas características sensoriais o cozimento é rápido e uniforme, há poucas fibras e reduzido potencial cianogênico (Mahungu, 1987; PeREIRA et al., 1985; LORENZI, 2003). Estas características estão associadas ao genótipo, às condiçôes ambientais favoráveis, e à idade da planta (LoRENZI, 2003).

Há um grande número de cultivares de mandioca de mesa no Brasil, muitas delas autóctones (LoRENZI, 1996). Sua escolha, no entanto depende da adaptação às condiçôes edafoclimáticas regionais e das características do mercado que se destina (LorenzI, 2003). A cultivar IAC 576-70 é amplamente adotada em lavouras comerciais de mandioca de mesa na Região Centro-Sul do Brasil. Possui bom desempenho agrícola em termos de produtividade, resistência à bacteriose (Xanthomonas axonopodis pv. manihotis Vauterin et al.), uniformidade das raízes e qualidade pós-colheita (Lorenzi e VAlle, 2002).

A mandioca de mesa é colhida preferencialmente com um ciclo vegetativo, oito a quatorze meses após o plantio (Lorenzi, 2003; Fukuda et al., 2006). Normalmente não é colhida antes de oito meses de idade, porque as raízes possuem diâmetro reduzido e não atingem padrão comercial, nem após quatorze meses, devido à redução nas qualidades sensoriais e culinárias (LorenzI, 1994). O ciclo longo, comparativamente a outros produtos hortícolas, retarda o retorno financeiro e deixa a cultura exposta a maiores riscos.

A influência da densidade populacional na produção de raízes de mandioca é relativamente bem estudada. No entanto, varia muito principalmente nas culturas de subsistência (FuKUDA et al., 2006). Observa-se em diversos trabalhos que a produtividade de raízes em função da densidade populacional varia segundo modelo de regressão quadrático. Assim, com o incremento da densidade populacional a produtividade aumenta até atingir um ponto de inflexão, a partir do qual, cai (Normanha e Pereira, 1950; Enyi, 1973; Cock et al., 1977; Mondardo et al., 1995; TAKahashi e Guerini, 1998). Verificam-se interaçóes significativas entre a produtividade de raízes, e a arquitetura da parte aérea (Cock et al., 1977; TÁvora et al., 1982), tipo de solo e época de colheita (Normanha e Pereira, 1952). No entanto, a maioria dos trabalhos com densidade populacional em mandioca concentra-se no manejo de culturas destinadas ao processamento industrial, cujo principal objetivo é maximizar a produtividade. Resultados concordantes mostram que diante de grandes variaçóes na densidade populacional ocorrem pequenas alteraçôes na produtividade de raízes.

Nos cultivos destinados à produção de mandioca de mesa, aspectos como tamanho e uniformidade das raízes e, principalmente, as características organolépticas são imprescindíveis. Dentre outros, esses fatores são os principais responsáveis pela qualidade da produção exigida na comercialização. No entanto, na maioria dos trabalhos publicados até o momento, não se avaliaram os efeitos da tecnologia de produção sobre essas características.

Considerando a plasticidade da produção de raízes de mandioca, pode-se explicar grande parte desses resultados. Em situação de menor competiçáo entre plantas tem-se o aumento substancial da produção individual de raízes devido à maior quantidade e tamanho das raízes, que demonstra a maior capacidade de dreno dos órgáos de armazenamento (BArros et al., 1978; CocK et al., 1977; Enyi, 1973; Hunt, 1977; Willians, 1972).

Em geral, nos solos de baixa fertilidade, as plantas de mandioca desenvolvem-se menos e são cultivadas em maiores densidades de plantio, enquanto em solos mais férteis, seu desenvolvimento é maior, justificando a utilização de menores densidades de plantio (Normanha e Pereira, 1950; Lorenzi, 2003; Mattos, 2006).

Segundo a classificação da Companhia de Entrepostos e Armazéns Gerais do Estado de São Paulo - CEAGESP, a mandioca é comercializada em caixas de $23 \mathrm{~kg}$ e padronizada em graúda, média e miúda, o que lhes confere variações nos preços. A classe graúda recebe a melhor cotação, a média valores intermediários e na classe miúda sáo praticados os menores preços (CERADA, 2005).

A qualidade das raízes de mandioca pode ser influenciada por diversos fatores. Com o aumento da densidade populacional, observa-se o decréscimo no número de raízes por planta (Cock et al., 1977; Enyi, 1972; Ayoola e MAKINDE, 2008), e também redução na massa média (Williams, 1974; Cock et al., 1977; Mondardo et al., 1995; Ayoola e Makinde, 2008).

Nas maiores densidades de plantio, verificam-se vantagens sobre o controle do mato. Nas altas populaçóes, foram observados menor período de mato-interferência e maior capacidade de competiçáo da cultura com as plantas infestantes (Peressin, 2010), reduzindo o tempo para o recobrimento do solo pela parte aérea da mandioca (Oliveira, 1998), com maior qualidade na produção de raízes, reduzindo os danos na colheita e a deterioração pós-colheita, promovendo maior tempo de comercialização (Peressin, 2010).

O objetivo do presente trabalho é analisar o efeito de densidades populacionais na produtividade e precocidade da produção de raízes comerciais de mandioca de mesa. 


\section{MATERIAL E MÉTODOS}

O experimento foi desenvolvido durante o período de julho de 2001 a novembro de 2002 , na latitude $22^{\circ} 40$ 'S, longitude $50^{\circ} 26^{\prime} \mathrm{W}$ e altitude de $563 \mathrm{~m}$. O clima da região é do tipo "Cwa", subtropical com inverno subúmido e verão quente e úmido. A precipitação pluvial e temperatura média anual são de $1.469 \mathrm{~mm}$ e $22^{\circ} \mathrm{C}$ respectivamente. O solo é do tipo Latossolo Vermelho- Escuro distroférrico, horizonte A moderado, de textura média. A cultivar utilizada foi a IAC 576-70, plantada com manivas-semente de $15 \mathrm{~cm}$ de comprimento.

Não foi realizada calagem, sendo a adubação de plantio feita com $300 \mathrm{~kg} \mathrm{ha}^{-1}$ da fórmula 4-20-20 + 0,5\% de zinco, conforme recomendação para o Estado de São Paulo (LoRENZI et al., 1996).

O experimento constituiu-se de fatorial duplo $6 \times 7$ com quatro repetiçóes, totalizando 42 tratamentos. $\mathrm{O}$ delineamento experimental empregado foi inteiramente casualizado em parcelas subdivididas. As parcelas foram formadas por seis épocas de colheita $(6,8,10,12,14$ e 16 meses após o plantio), inteiramente casualizadas, e as subparcelas formadas por sete densidades populacionais $(5.000,5.714$, $6.667,8.000,10.000,13.333$ e 20.000 plantas ha $^{-1}$ ), distribuídas de maneira sistematizada dentro de cada parcela, conferindo-lhes o formato de trapézio isósceles (Figura 1).

As parcelas (trapézios) constituíram-se de 90 plantas distribuídas em nove linhas de 10 plantas. As sete linhas centrais de cada parcela foram colhidas como subparcelas, e as duas laterais descartadas como bordaduras (Figura 1). As subparcelas constituíram-se em linhas de dez plantas, com espaçamento fixo entre as linhas e variável entre as plantas na linha, proporcionando as densidades populacionais propostas. As densidades derivaram-se da variaçâo crescente de $0,25 \mathrm{~m}$ no espaçamento entre as plantas, da base menor para a base maior da parcela trapezoidal (Figura 1).

Foram colhidas 10 plantas de cada subparcela. Dentre as raízes, avaliaram-se a produção total de raízes tuberosas e a produção de raízes comerciais acima da classe miúda comercializada no CEAGESP, considerando como descarte as raízes abaixo desse padrão (CEAGESP, 2003).

Os resultados foram avaliados por meio de regressão, ajustando-se os dados coletados a equaçóes típicas de crescimento (não lineares). Os ajustes foram feitos inicialmente por planta, em nível de subparcela (densidades populacionais) ao modelo de regressão $\mathrm{y}=\mathrm{a} \mathrm{x}^{\mathrm{b}}$, pela representatividade ao fenômeno biológico em estudo. Os valores ajustados por planta nas densidades avaliadas, foram utilizados para o ajuste em nível de parcela (colheitas), por meio do modelo de regressão polinomial do terceiro grau, $y=a+b x+b_{1} x^{2}+b_{2} x^{3}$, por representar a dinâmica de crescimento de raízes de mandioca no tempo.

Realizados os ajustes em função das parcelas (colheitas) e em função das subparcelas (densidades populacionais), os valores estimados pelas equaçóes foram utilizados para a estimativa da produtividade por hectare, para uma melhor distribuiçáo do erro estatístico. Todo o processo de análise e interpretação foi viabilizado pela utilização dos seguintes programas de computador: Curvexpert ${ }^{\odot} 1.3$ (Hiams, 1997); Origin ${ }^{\oplus} 6.0$ (Microcal Softwere Corporation); Statistica ${ }^{\oplus} 6.0$ (Statsoft Inc).

\section{RESULTADOS E DISCUSSÃO}

\section{Produção individual de plantas}

As produçóes médias de raízes totais por planta e raízes comerciais podem ser observadas nas tabelas 1 e 2 . Os dados de produção individual por planta, ajustaram-se bem aos modelos de regressão $\mathrm{y}=\mathrm{a} \mathrm{x}^{\mathrm{b}}$ e $\mathrm{y}=\mathrm{a}+\mathrm{bx}+$ $\mathrm{b}_{1} \mathrm{x}^{2}+\mathrm{b}_{2} \mathrm{x}^{3}$, utilizados nos ajustes da produção total e comercial de raízes. Os coeficientes de determinaçáo das equaçôes utilizadas para os ajustes são apresentados nas tabelas 3 e 4 .

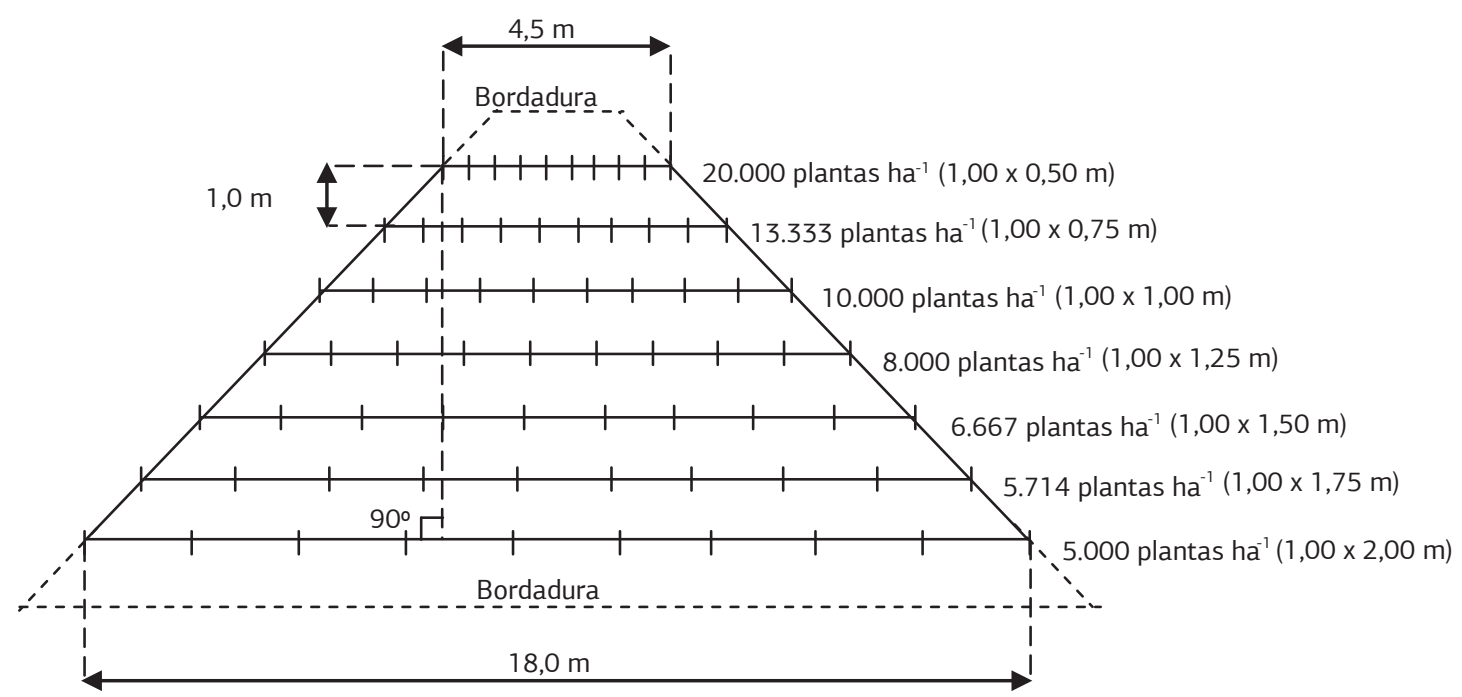

Figura 1. Modelo da parcela (Trapézio isóscele) e das subparcelas (linhas de 10 plantas), para estudo de sete densidades populacionais. 
Tabela 1. Produção média por planta de raízes mandioca de mesa, obtida nas subparcelas, nas seis colheitas avaliadas, em 2001/2002

\begin{tabular}{|lcccccccc}
$\begin{array}{l}\text { Densidades } \\
\text { Plantas ha }\end{array}$ & $\mathbf{6}$ meses & $\mathbf{8}$ meses & $\mathbf{1 0}$ meses & $\mathbf{1 2}$ meses & $\mathbf{1 4}$ meses & $\mathbf{1 6}$ meses & Média \\
\hline 5.000 & & & & $\mathbf{k g ~ p l a n t a}^{-1}$ & & & \\
\hline 5.714 & 1,731 & 3,380 & 3,808 & 4,099 & 4,152 & 4,716 & 3,648 \\
\hline 6.667 & 1,680 & 2,889 & 3,373 & 3,898 & 3,648 & 4,813 & 3,383 \\
\hline 8.000 & 1,264 & 2,740 & 2,079 & 3,049 & 2,795 & 3,416 & 2,557 \\
\hline 10.000 & 1,332 & 2,255 & 2,390 & 2,902 & 2,549 & 3,043 & 2,412 \\
\hline 13.333 & 0,985 & 1,799 & 1,716 & 2,216 & 1,843 & 2,552 & 1,852 \\
\hline 20.000 & 0,914 & 1,469 & 1,468 & 1,991 & 2,208 & 1,937 & 1,665 \\
\hline Média & 0,661 & 0,661 & 0,892 & 1,049 & 1,268 & 1,125 & 1,684 \\
\hline
\end{tabular}

Tabela 2. Produção média de raízes comerciais por planta, obtida nas subparcelas, nas seis colheitas avaliadas, em 2001/2002

\begin{tabular}{|lccccccccc}
$\begin{array}{l}\text { Densidades } \\
\text { Plantas ha }\end{array}$ & $\mathbf{6}$ meses & $\mathbf{8}$ meses & $\mathbf{1 0}$ meses & $\mathbf{1 2}$ meses & $\mathbf{1 4}$ meses & $\mathbf{1 6}$ meses & Média \\
\hline 5.000 & & & \multicolumn{7}{c}{$\mathbf{k g ~ p l a n t a}^{-1}$} \\
\hline 5.714 & 0,783 & 2,132 & 2,508 & 3,335 & 3,079 & 4,220 & 2,676 \\
\hline 6.667 & 0,614 & 1,851 & 2,280 & 3,010 & 2,783 & 4,327 & 2,478 \\
\hline 8.000 & 0,581 & 1,650 & 1,189 & 2,285 & 1,811 & 2,733 & 1,708 \\
\hline 10.000 & 0,579 & 1,167 & 1,352 & 2,149 & 1,763 & 2,310 & 1,553 \\
\hline 13.333 & 0,399 & 0,941 & 1,015 & 1,456 & 1,215 & 1,870 & 1,149 \\
\hline 20.000 & 0,257 & 0,623 & 0,691 & 1,204 & 1,411 & 1,441 & 0,938 \\
\hline Média & 0,222 & 0,345 & 0,398 & 0,757 & 0,611 & 1,045 & 0,563 \\
\hline
\end{tabular}

Foram observadas semelhanças nas curvas de regressão para a produção total e comercial por planta em função da densidade populacional em todas as épocas de colheita, com acentuado decréscimo na produção de raízes nas populaçôes com até 13.000 planta ha ${ }^{-1}$ e decréscimos menores até 20.000 plantas $_{\text {ha }}{ }^{-1}$. Esse fato evidencia a competição entre plantas de mandioca, e está de acordo com Cock et al. (1979), que relata decréscimo na produçáo de raízes tuberosas e acréscimo na produção de parte aérea quando há restriçóes de luminosidade (Figura 2).

A produção total de raízes em plantas individuais caiu de 2,21 para $0,73 \mathrm{~kg}_{\text {planta }}{ }^{-1}$ ( $67 \%$ de reduçáo) quando a população foi aumentada de 5.000 para 20.000 plantas $\mathrm{ha}^{-1}$ respectivamente aos seis meses, e de 3,35 para $0,91 \mathrm{~kg}$ planta $^{-1}(73 \%)$, nas mesmas densidades, aos oito meses. No período mais favorável ao desenvolvimento vegetativo das plantas de mandioca, época mais quente e úmida nos ambientes subtropicais, foram observadas as maiores taxas de acumulação de carboidratos nas raízes (LoRENZI, 2003; Alves, 2006). Pode-se observar também nesse período, o maior efeito de densidades populacionais na produção de raízes por planta. Por outro lado, durante a época de menor atividade fisiológica, que coincide com época mais fria e seca do ano, nesses ambientes, os efeitos das densidades populacionais na produçáo de raízes por planta foram menos pronunciados, como se pode observar nas colheitas realizadas aos 10 e 14 meses, cujas curvas de produção tornam-se bastante próximas (Figura 2a), conforme também relatam outros autores (CONCEIÇÃO), 1981; LORENZI, 2003; Alves, 2006).

O efeito da densidade populacional foi ainda mais expressivo na produçâo de raízes comerciais em plantas individuais (Figura $2 \mathrm{~b}$ ). Nas colheitas precoces, aos seis meses, a produção comercial caiu de 1,19 para $0,25 \mathrm{~kg}_{\text {planta }}{ }^{-1}$, quando a densidade populacional passou de 5.000 para 20.000 plantas ha ${ }^{-1}$ (79\% de redução); e, aos oito meses passou de 2,22 para 0,36 kg planta ${ }^{-1}$ nas mesmas densidades (84\%). Em colheitas tardias, aos 16 meses, a densidade populacional também teve efeito marcante, quando a produçấo caiu de 3,82 para $0,80 \mathrm{~kg}$ planta $^{-1}$, com 5.000 e 20.000 plantas ha ${ }^{-1}$ respectivamente (79\%). Portanto, esses resultados indicam que plantas de mandioca podem produzir raízes maiores, consequentemente com melhor padrão comercial, se forem submetidas à menor competição, plantadas em espaçamentos maiores.

\section{Produção relativa entre raízes totais e comerciais}

De maneira distinta dos cereais, as plantas de mandioca possuem ciclo mais longo, e o acúmulo de carboidratos nas raízes ocorre durante todo o ciclo de desenvolvimento. Não há, portanto, um período bem definido de produção de raízes, como ocorre nos cereais, após o florescimento (Cock, 1977; Alves, 2002). Durante 
Tabela 3. Coeficientes da funçâo $\mathrm{y}=\mathrm{ax}^{\mathrm{b}}$, utilizada no ajuste dos dados de produção total e de raízes comerciais de mandioca de mesa em $\mathrm{kg}_{\text {planta }}{ }^{-1}$. Ajuste em função das densidades de plantio (subparcelas)

\begin{tabular}{|c|c|c|c|c|c|c|c|}
\hline \multirow{3}{*}{ Colheitas (dias) } & \multirow{3}{*}{ Repetições } & \multicolumn{6}{|c|}{ Coeficientes da função $y=a x^{b}$} \\
\hline & & \multicolumn{3}{|c|}{ Produção total de raízes } & \multicolumn{3}{|c|}{ Produção de raízes comerciais } \\
\hline & & $\mathbf{a}$ & b & $r^{2}$ & a & b & $\mathbf{r}^{2}$ \\
\hline 180 & 1 & 171,97 & $-5,50^{-1}$ & 0,79 & 1126,34 & $-8,44^{-1}$ & 0,92 \\
\hline 180 & 2 & 1527,52 & $-7,99^{-1}$ & 0,92 & 11562,36 & $-1,14$ & 0,96 \\
\hline 180 & 3 & 587,51 & $-6,77^{-1}$ & 0,97 & 12397,90 & $-1,11$ & 0,86 \\
\hline 180 & 4 & 2277,68 & $-8,35^{-1}$ & 0,79 & 95,17 & $-6,01^{-1}$ & 0,74 \\
\hline 240 & 1 & 2904,32 & $-8,20^{-1}$ & 0,91 & 2935,70 & $-9,62^{-1}$ & 0,69 \\
\hline 240 & 2 & 58112,08 & $-1,12$ & 0,95 & 376164,90 & $-1,39$ & 0,92 \\
\hline 240 & 3 & 1039,63 & $-6,79^{-1}$ & 0,86 & 1114,78 & $-7,30^{-1}$ & 0,71 \\
\hline 240 & 4 & 10312,45 & $-9,41^{-1}$ & 0,77 & 63073853,00 & $-1,98$ & 0,85 \\
\hline 300 & 1 & 169837,50 & $-1,26$ & 0,83 & 53621436,00 & $-1,97$ & 0,88 \\
\hline 300 & 2 & 17951,53 & $-1,00$ & 0,86 & 1458002,00 & $-1,56$ & 0,85 \\
\hline 300 & 3 & 15735,87 & $-9,80$ & 0,82 & 28429,55 & $-1,11$ & 0,85 \\
\hline 300 & 4 & 6152,69 & $-8,77^{-1}$ & 0,78 & 32103,45 & $-1,12$ & 0,69 \\
\hline 360 & 1 & 7868,47 & $-8,75^{-1}$ & 0,90 & 55579,62 & $-1,12$ & 0,96 \\
\hline 360 & 2 & 441,69 & $-5,77^{-1}$ & 0,60 & 4744,55 & $-8,85^{-1}$ & 0,67 \\
\hline 360 & 3 & 54070,86 & $-1,11$ & 0,87 & 470938,60 & $-1,42$ & 0,94 \\
\hline 360 & 4 & 3240,67 & $-7,72^{-1}$ & 0,94 & 26496,47 & $-1,03$ & 0,96 \\
\hline 420 & 1 & 10283,69 & $-9,16^{-1}$ & 0,95 & 25136,90 & $-1,05$ & 0,94 \\
\hline 420 & 2 & 16286,25 & $-9,67^{-1}$ & 0,71 & 125353,20 & $-1,24$ & 0,76 \\
\hline 420 & 3 & 16890,72 & $-9,86^{-1}$ & 0,81 & 149430,30 & $-1,28$ & 0,79 \\
\hline 420 & 4 & 1561,71 & $-7,09^{-1}$ & 0,89 & 5316,20 & $-8,98^{-1}$ & 0,88 \\
\hline 480 & 1 & 7001,41 & $-8,68^{-1}$ & 0,80 & 17831,83 & $-1,00$ & 0,74 \\
\hline 480 & 2 & 7258,83 & $-8,52^{-1}$ & 0,89 & 93678,72 & $-1,16$ & 0,92 \\
\hline 480 & 3 & 7346,38 & $-8,61^{-1}$ & 0,84 & 139864,60 & $-1,22$ & 0,90 \\
\hline 480 & 4 & 21313,62 & $-9,79^{-1}$ & 0,88 & 469973,66 & $-1,35$ & 0,90 \\
\hline
\end{tabular}

Tabela 4. Coeficientes da função $\mathrm{y}=\mathrm{a}+\mathrm{b} \mathrm{x}+\mathrm{b}_{1} \mathrm{x}^{2}+\mathrm{b}_{2} \mathrm{x}^{3}$, ajustada aos dados estimados no ajuste inicial, para a produção total e produção comercial de raízes de mandioca de mesa em kg planta ${ }^{-1}$. Ajuste em função das colheitas (parcelas)

\begin{tabular}{|c|c|c|c|c|c|c|c|c|c|c|}
\hline \multirow{3}{*}{$\begin{array}{l}\text { Densidades } \\
\text { Plantas ha }\end{array}$} & \multicolumn{10}{|c|}{ Coeficientes da função $y=a+b x+b_{1} x^{2}+b_{2} x^{3}$} \\
\hline & \multicolumn{5}{|c|}{ Produção total de raízes } & \multicolumn{5}{|c|}{ Produção de raízes comerciais } \\
\hline & a & b & $b_{1}$ & $b_{2}$ & $r^{2}$ & a & b & $b_{1}$ & $b_{2}$ & $\mathbf{r}^{2}$ \\
\hline 20.000 & $-3,66^{-1}$ & $9,14^{-3}$ & $-2,02^{-5}$ & $1,79^{-8}$ & 0,85 & $7.96^{-3}$ & $8.55^{-4}$ & $3.41^{-6}$ & $-3.69^{-9}$ & 0.89 \\
\hline 13.333 & $-1,41$ & $2,16^{-2}$ & $-5,43^{-5}$ & $4,93^{-8}$ & 0,90 & $-6.05^{-1}$ & $7.54^{-3}$ & $-1.38^{-5}$ & $1.28^{-8}$ & 0.92 \\
\hline 10.000 & $-2,62$ & $3,55^{-2}$ & $-9,25^{-5}$ & $8,45^{-8}$ & 0,94 & -1.57 & $1.79^{-2}$ & $-4.21^{-5}$ & $4.00^{-8}$ & 0.93 \\
\hline 8.000 & $-3,94$ & $5,04^{-2}$ & $-1,34^{-4}$ & $1,22^{-7}$ & 0,96 & -2.86 & $3.16^{-2}$ & $-8.07^{-5}$ & $7.70^{-8}$ & 0.94 \\
\hline 6.667 & $-5,35$ & $6,62^{-2}$ & $-1,78^{-4}$ & $1,63^{-7}$ & 0,97 & -4.45 & $4.86^{-2}$ & $-1.29^{-4}$ & $1.23^{-7}$ & 0.95 \\
\hline 5.714 & $-6,84$ & $8,26^{-2}$ & $-2,23^{-4}$ & $2,05^{-7}$ & 0,98 & -6.36 & $6.88^{-2}$ & $-1.87^{-4}$ & $1.79^{-7}$ & 0.96 \\
\hline 5.000 & $-8,37$ & $9,95^{-2}$ & $-2,70^{-4}$ & $2,48^{-7}$ & 0,98 & -8.57 & $9.22^{-2}$ & $-2.56^{-4}$ & $2.44^{-7}$ & 0.96 \\
\hline
\end{tabular}

o ciclo de desenvolvimento, a planta de mandioca possui concomitantemente dois principais drenos de fotoassimilados: as raízes tuberosas que são os principais órgáos de armazenamento, e a parte aérea, que consome grande parte dos açúcares produzidos na fotossíntese para o desenvolvimento das folhas e dos caules (Williams, 1972; Alves, 2002; Lorenzi, 2003).
O número de raízes tuberosas é definido principalmente nos primeiros 120 dias após o plantio (LoRENZI, 2003); após esse período, verifica-se o crescimento contínuo dessas raízes pelo acúmulo de carboidratos. A fase em que ocorre o maior desenvolvimento das raízes vai do sexto ao décimo mês após o plantio, quando se observa a maior taxa de translocação de carboidratos para as raízes (ConCeIção, 
(a)

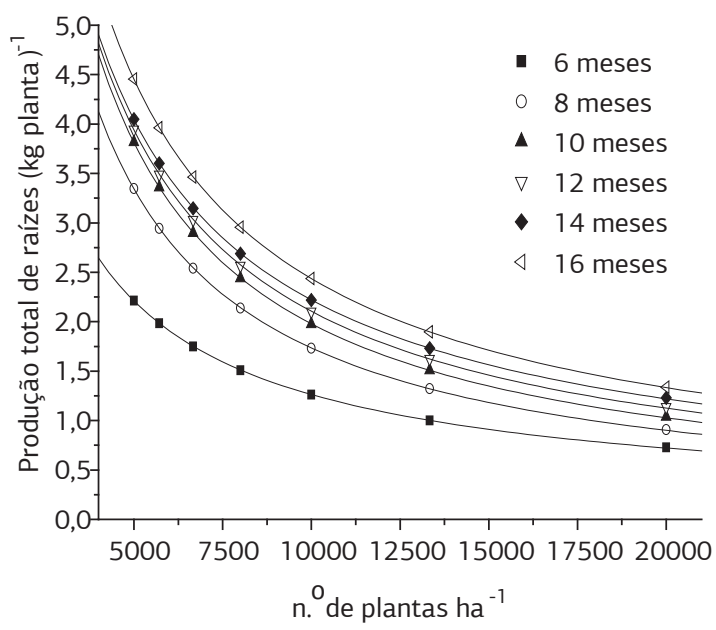

(b)

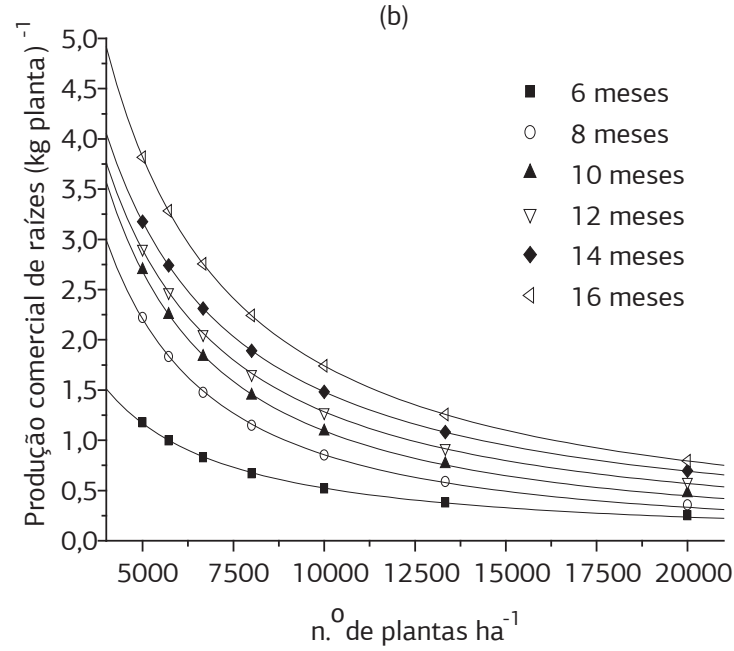

Figura 2. Estimativa da produção total (a) e comercial de raízes de mandioca (b) por plantas (kg planta-1) e equaçóes de regressão, nas densidades populacionais avaliadas (plantas $\mathrm{ha}^{-1}$ ) em seis épocas de colheita (meses), em 2001/2002. Cada ponto representa os valores estimados pelas equações determinadas no ajuste para densidades (subparcela) e colheitas (parcela) (Tabelas 3 e 4). Equaçóes de regressão: (a) 6 meses $y=2137,69 \cdot x^{-8,07-01}\left(r^{2}=1,00\right), 8$ meses $y=10541,27 \cdot x^{-9,46-01} \quad\left(r^{2}=1,00\right), 10$ meses $y=11935,39 \cdot x^{-9,45-01} \quad\left(r^{2}=1,00\right)$, 12 meses $y=8638,11 \cdot x^{-9,03-01}\left(r^{2}=1,00\right), 14$ meses $y=6378,47 \cdot x^{-8,65-01}\left(r^{2}=1,00\right)$ e 16 meses $y=7327,93 \cdot x^{-8,70-01}\left(r^{2}=1,00\right)$; (b) 6 meses $y=21962,56 \cdot x^{-1,16}$ $\left(r^{2}=1,00\right), 8$ meses $y=248340,80 \cdot x^{-1,37}\left(r^{2}=1,00\right), 10$ meses $y=160386,19 \cdot x^{-1,29},\left(r^{2}=1,00\right), 12$ meses $y=63033,05 \cdot x^{-1,17}\left(r^{2}=1,00\right), 14$ meses $\mathrm{y}=36689,47 \cdot \mathrm{x}^{-1,10}\left(\mathrm{r}^{2}=1,00\right)$ e 16 meses $\mathrm{y}=58913,20 \cdot \mathrm{x}^{-1,13}\left(\mathrm{r}^{2}=1,00\right)$.

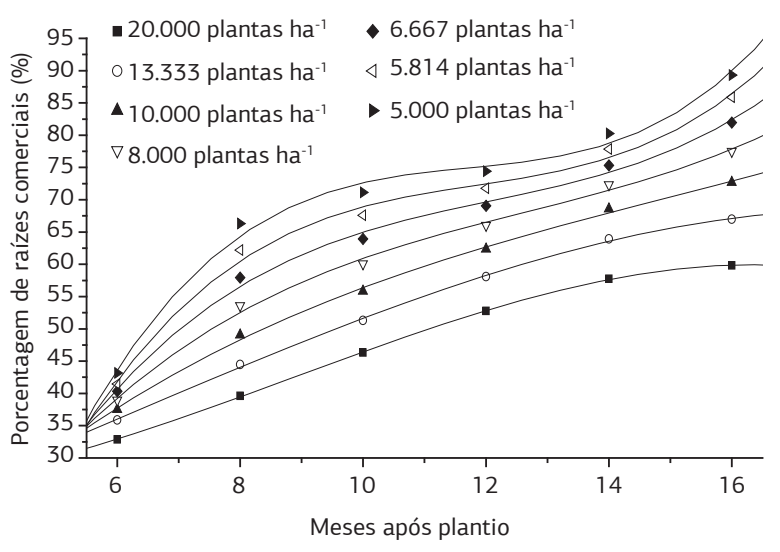

Figura 3. Estimativa da porcentagem de raízes comerciais de mandioca de mesa (\%) em função das épocas de colheita (meses), em 2001/2002, nas diferentes densidades populacionais (plantas $\left.\mathrm{ha}^{-1}\right)$. Cada ponto representa a diferença em porcentagem da produção total e comercial de raízes, estimados pelas equaçóes de ajuste por planta nas densidades (subparcela) e colheitas (parcela) (Tabelas 3 e 4). Equações de regressão, 20.000 plantas ha ${ }^{-1} \mathrm{y}$ $=26,03-1,44 \cdot x+0,56 \cdot x^{2}-0,02 \cdot x^{3} \quad\left(r^{2}=1,00\right), 13.333$ plantas ha ${ }^{-1}$ $y=13,38+3,25 \cdot x+0,16 . x^{2}-0,01 \cdot x^{3} \quad\left(r^{2}=1,00\right), 10.000$ plantas ha ${ }^{-1}$ $y=-6,15+12,48 \cdot x-0,67 \cdot x^{2}-0,02 \cdot x^{3} \quad\left(r^{2}=1,00\right), 8.000$ plantas ha ${ }^{-1}$ $y=-50,68+23,37 \cdot x-1,66 \cdot x^{2}+0,04 \cdot x^{3}\left(r^{2}=1,00\right), 6.667$ plantas $h^{-1}$ $y=-87,81+32,23 \cdot x-2,76 \cdot x^{2}+0,08 \cdot x^{3} \quad\left(r^{2}=1,00\right), 5.814$ plantas $h^{-1}$ $y=-127,79+47,90 \cdot x-3,93 \cdot x^{2}+0,11 \cdot x^{3}\left(r^{2}=0,99\right)$ e 5.000 plantas $h^{-1}$ $y=-159,09+58,11 \cdot x-4,88 \cdot x^{2}+0,14 \cdot x^{3}\left(r^{2}=0,99\right)$.

1981; Alves, 2002). Como se observa na figura 3, o desenvolvimento das raízes foi influenciado pela competição entre as plantas, que refletiu em maior porcentagem de raízes comerciais nas baixas densidades avaliadas (Figura 3).

Nas menores densidades, a capacidade competitiva de dreno das raízes é superior em relação aos pontos de cresci- mento da parte aérea de plantas submetidas à maior competição. Observou-se que a porcentagem de raízes comerciais aumentou com a redução da densidade de plantio (Figura 3). Aos seis meses houve um aumento de 33\% para $43 \%$ de raízes comercias em relação à produção total, com a redução da população de 20.000 para 5.000 plantas ha $^{-1}$. O mesmo efeito foi observado em todas as épocas de colheita, e aos oito meses houve aumento de $40 \%$ para $66 \%$, e aos 16 meses de $60 \%$ para $89 \%$ de raízes comerciais, para as densidades de 20.000 e 5.000 plantas ha ${ }^{-1}$ respectivamente.

Esses resultados inferem que a intensidade de competição entre plantas influi significativamente no desenvolvimento das raízes, como observado por Cock et al. (1979). Raízes classificadas como descarte da produção comercial em altas densidades, em baixas densidades desenvolveram-se melhor, atingindo padrão comercial e reduzindo a taxa de descarte (Figura 3).

\section{Produtividade}

A produção total de raízes por hectare em função das densidades populacionais estudadas pôde ser modulada por equaçóes polinomiais de segundo grau, em todas as épocas de colheita (Figura 4a). Essa observação está de acordo com vários autores (Cock et al., 1977; ENYI, 1973; Mondardo et al., 1995; Normanha e Pereira, 1950), embora haja variaçôes na determinação da população ideal para obtenção da máxima produtividade. Essa variação ocorre principalmente pelas diferentes condiçóes ambientais e as cultivares avaliadas nesses estudos. A maior produção estimada foi de 26,8 t ha $^{-1}$ com 20.000 plantas ha ${ }^{-1}$ aos 16 meses. Na mesma 
época de colheita, nas densidades de 5.000 e 10.000 plantas ha $\mathrm{a}^{-1}$ produziram-se, respectivamente, $22,3 \mathrm{t} \mathrm{ha}^{-1} \mathrm{e}$ $24,4 \mathrm{t} \mathrm{ha}^{-1}$. Náo foram observados os pontos de inflexão das curvas de regressão para todas as épocas de colheita avaliadas e o potencial máximo de produtividade náo pode ser observado, mesmo na ampla faixa de densidades avaliadas nesse trabalho. Pelas curvaturas das regressōes quadráticas, observa-se que, com grandes alteraçốes no número de plantas, os efeitos não pouco expressivos na produção total de raízes. Observa-se, assim, a alta capacidade adaptativa das plantas de mandioca em diferentes níveis de competição por água, luz e nutrientes, como afirmam diversos autores (Howeler, 2002; Lorenzi, 2003; Alves 2006), que lhes conferem elevada taxa de compensação quanto à produtividade de raízes por hectare. Essa característica, embora não seja evidente na produção de raízes por planta (Figura 2a), ao estimar-se a produtividade por hectare são originadas produtividades pouco contrastantes (Figura 4a).

$\mathrm{O}$ efeito da densidade populacional na produção de raízes comerciais foi diferente do verificado na produção total de raízes (Figura 4a, b). Obtiveram-se as maiores produtividades de raízes comerciais nas menores densidades populacionais, em qualquer época de colheita estudada. Em colheitas precoces, a produtividade comercial aumentou de 5,0 t ha ${ }^{-1}$ para 5,9 t ha ${ }^{-1}$ (6 meses) com a redução do número de plantas de 20.000 para 5.000. Na colheita aos oito meses, a produtividade comercial variou de 7,2 $\mathrm{t} \mathrm{ha}^{-1}$ para $11,1 \mathrm{t} \mathrm{ha}^{-1}$, nas mesmas densidades. Aos dez meses a produção aumentou de 9,4 $\mathrm{t} \mathrm{ha}^{-1}$ com 20.000 plantas ha $^{-1}$ para 10,9 t ha ${ }^{-1}$ com 10.000 plantas ha ${ }^{-1}$, atingindo 13,5 t ha ${ }^{-1}$ com 5.000 plantas ha $^{-1}$. Esses resultados demonstraram que nas menores densidades de plantio, foram obtidos os maiores níveis de produtividade, mesmo nas colheitas precoces. Já nas colheitas tardias, 14 a 16 meses após o plantio, também foram obtidas as maiores produtividades de raízes comerciais nas menores densidades populacionais (Figura 4b); todavia, nessas épocas (colheitas tardias) compromete-se a qualidade culinária e sensorial das raízes de mandioca de mesa (LoRENZI, 2003).

A maioria dos resultados observados na literatura relata aumento da produtividade total de raízes de mandioca com aumento da densidade de plantio até certa população, a partir da qual se observa redução na produtividade (Normanha e Pereira, 1950; Enyi, 1973; Cock et al., 1977; Mondardo et al., 1995; TaKahashi e Guerini, 1998). Tais resultados são também observados na produtividade total de raízes, embora náo se tenha atingido o ponto de inflexão da curva de regressão quadrática na faixa de densidades estudadas (Figura 4a). No entanto, esses resultados não devem ser comparados com a produção de raízes comerciais, por se tratar de produtos distintos. Não foram verificados na literatura trabalhos que considerem a produção comercial de raízes de mandioca de mesa.

As maiores produtividades de raízes comerciais foram observadas nas menores densidades estudadas (Figura 4b). Esses resultados justificam-se pela menor taxa de descarte nessas populaçóes (Figura 3), e pela maior capacidade de dreno (Соск, 1977) e desenvolvimento das raízes das plantas (a)

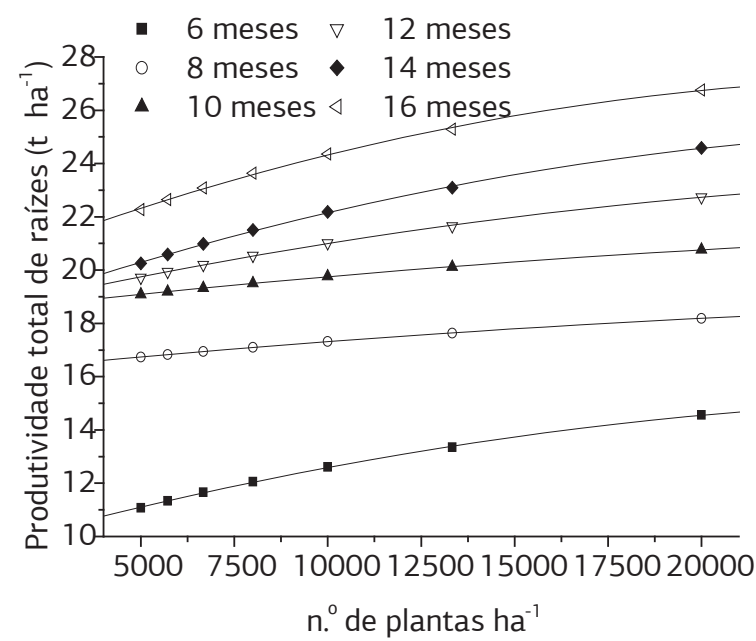

(b)

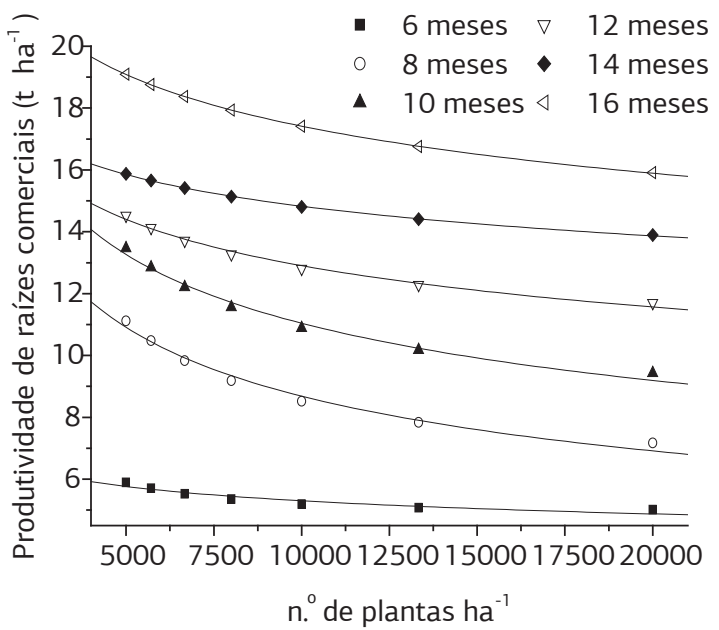

Figura 4. Estimativa da produtividade total (a) e comercial de raízes de mandioca (b) por hectare ( $\mathrm{t}$ ha ${ }^{-1}$ ) e equaçóes de regressão, nas densidades populacionais avaliadas (plantas ha ${ }^{-1}$ ) em seis épocas de colheita (meses), em 2001/2002. Cada ponto representa os valores estimados pelas equaçóes determinadas no ajuste por planta nas densidades (subparcela) e colheitas (parcela), multiplicados pelas respectivas densidades (tabelas 3 e 4). Equaçóes de regressão: (a) 6 meses $y=9281,70+3,98^{-01} \cdot x^{2}+-6,73^{-06} \cdot x^{2}\left(r^{2}=1,00\right), 8$ meses $y=16076,57+1,42^{-01}$. $\mathrm{x}^{2}+-1,82^{-06} \cdot \mathrm{x}^{2}\left(\mathrm{r}^{2}=1,00\right), 10$ meses $\mathrm{y}=18329,10+1,63^{-01} \cdot \mathrm{x}^{2}+-2,06^{-06} \cdot \mathrm{x}^{2}\left(\mathrm{r}^{2}=1,00\right), 12$ meses $\mathrm{y}=18235,49+3,27^{-01} \cdot \mathrm{x}^{2}+-5,13^{-06} \cdot \mathrm{x}^{2}\left(\mathrm{r}^{2}=1,00\right), 14$ meses $y=17996,65+5,03^{-01} \cdot x^{2}+-8,70^{-06} \cdot x^{2}\left(r^{2}=1,00\right), 16$ meses $y=19809,23+5,56^{-01} \cdot x^{2}+-1,04^{-05} \cdot x^{2} \quad\left(r^{2}=1,00\right) ;(b) 6$ meses $y=16103,4$. $x^{-0,1206}$ $\left(r^{2}=0,91\right), 8$ meses $y=179595,5 \cdot x^{-0,32887}\left(r^{2}=0,99\right), 10$ meses $y=126118,6 \cdot x^{-0,26442}\left(r^{2}=0,99\right), 12$ meses $y=55364,27 \cdot x^{-0,15811}\left(r^{2}=0,99\right), 14$ meses $\mathrm{y}=36062,98 \cdot \mathrm{x}^{-0,0965}\left(\mathrm{r}^{2}=1,00\right), 16$ meses $\mathrm{y}=58748,89 \cdot \mathrm{x}^{-0,13201}\left(\mathrm{r}^{2}=1,00\right)$. 
(a)

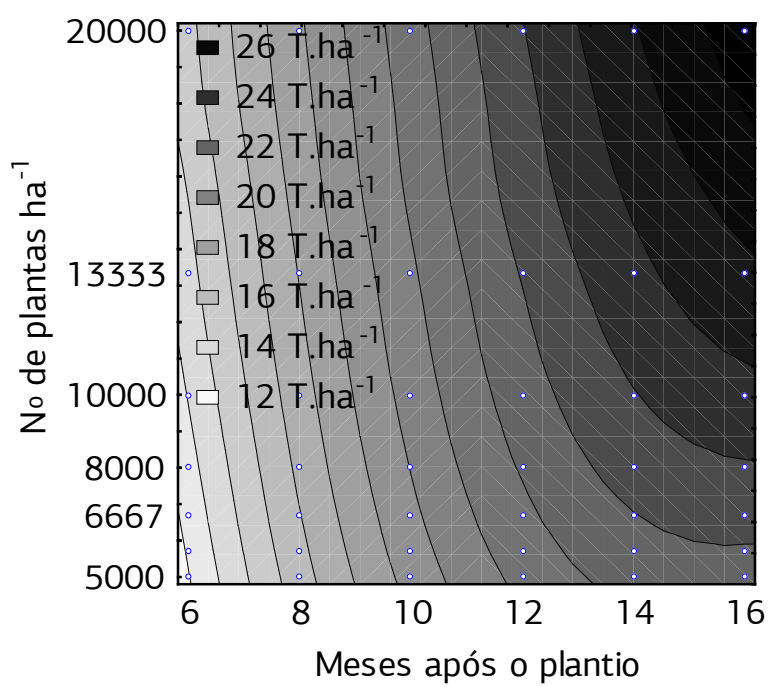

(b)

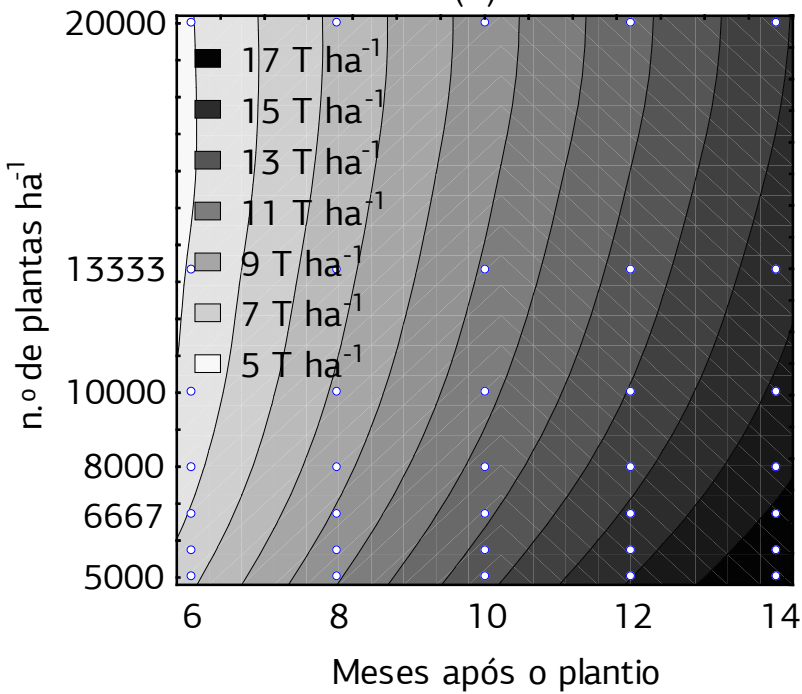

Figura 5. Superfícies de resposta estimada ( $\mathrm{t} \mathrm{ha}^{-1}$ ) em função das densidades populacionais e épocas de colheita, em 2001/2002. (a) Produção total de raízes de mandioca de mesa. (b) Produção de raízes comerciais. Os valores utilizados na superfície representam os valores estimados pelas equaçóes determinadas no ajuste por planta nas densidades (subparcela) e colheitas (parcela), multiplicados pelas respectivas densidades (Tabelas 3 e 4).

submetidas à menor competição espacial (Williams, 1974; Mondardo et al., 1995; Ayoola e Makinde, 2008).

A influência conjunta da densidade populacional e idade das plantas por ocasiáo da colheita, sobre a produçáo de raízes, pode ser mais bem analisada por meio de superfícies de resposta (Figura 5a). Altas produtividades puderam ser obtidas pela combinação de altas densidades populacionais e longos períodos de cultivo. Observaramse produtividades superiores a $26 \mathrm{t} \mathrm{ha}^{-1}$ somente com populaçốes acima de 13.333 plantas ha ${ }^{-1}$, cultivadas por 14 meses ou mais. Com 5.000 plantas ha ${ }^{-1}$, a produtividade máxima atingida oscilou entre 22 e $23 \mathrm{t} \mathrm{ha}^{-1}$, com colheita aos 14 a 16 meses respectivamente.

Em relação à produção comercial de raízes, a tendência observada foi inversa à produção total. Obteve-se a máxima produçấo de raízes comerciais com 19,1 t ha ${ }^{-1}$, aos 14 meses com a densidade de 5.000 plantas ha ${ }^{-1}$ (Figura 5b). Em colheitas precoces, ao redor de oito meses, observaram-se produções entre 9 e $10 \mathrm{t} \mathrm{ha}^{-1}$ de raízes comerciais somente com populaçóes inferiores a 7.000 plantas ha ${ }^{-1}$. Nas colheitas precoces (6 a 10 meses), foram observadas as maiores produçóes de raízes comerciais nas menores densidades populacionais estudadas (Figura 5b). Esse aumento ocorreu principalmente pelas menores taxas de descarte observadas nesses tratamentos (Figura 3).

Tais resultados demonstraram a possibilidade de obtenção de maiores produçóes comerciais de raízes de mandioca de mesa com o uso de baixas densidades de plantio, mesmo em colheitas precoces (6, 8 e 10 meses após o plantio). Colheitas precoces proporcionam ainda, menor teor de fibras, menor tempo de cozimento e melhor qualidade sensorial das raízes produzidas (LoRENZI, 1994; Cerada, 2005).

\section{CONCLUSÃO}

Baixas densidades de plantio podem ser utilizadas para a produção precoce de raízes comerciais de mandioca de mesa (6, 8 e 10 meses após o plantio).

A maior densidade populacional (20.000 plantas $\left.\mathrm{ha}^{-1}\right)$ resulta em maior produtividade total de raízes, independentemente da época de colheita, porém com menores rendimentos de raízes comerciais.

Menores densidades de plantio aumentam a produção de raízes comerciais em relação à produção total.

Plantas individuais submetidas à menor competição têm maior produção total e comercial de raízes, principalmente em colheitas precoces.

\section{AGRADECIMENTOS}

Os autores agradecem à Fundação de Amparo à Pesquisa do Estado de São Paulo (FAPESP) e à Coordenação de Aperfeiçoamento de Pessoal de Nível Superior (CAPES) pelo apoio financeiro ao projeto de pesquisa; ao Dr. Armando Conagin, pesquisador científico aposentado da antiga Seção de Técnica Experimental e Cálculo do Instituto Agronômico, pela discussão e orientação nas análises estatísticas.

\section{REFERÊNCIAS}

ALVES, A.A.C. Cassava Botany and Physiology. In: HILLOCKS, R.J.; THRESH, J.M.; BELLOTTI, A.C. (Ed.). Cassava: Biology, Production and Utilization. Wallingford: CABI Publishing, 2002. p.67-89. 
ALVES, A.A.C. Fisiologia da mandioca. In: SOUZA. L.S. Aspectos socioeconômicos e agronômicos da mandioca. Cruz das Almas: Embrapa Mandioca e Fruticultura Tropical, 2006. p. 138-169.

AYOOLA, O.T.; MAKINDE, E.A. Influence of cassava population density on the growth and yield performance of cassava-maize intercrop with a relayed cowpea. Tropical and Subtropical Agroecosystems, v.8, p.235-241, 2008.

BARROS, R.S.; MERCÊS, W.C.; ALVIM, R. Sink strength and cassava productivity. Hortscience, v.13, p.474-475, 1978.

CEAGESP (Companhia de Entrepostos e Armazéns Gerais do Estado de São Paulo). Preços praticados no CEAGESP. São Paulo: 2003. Disponível em: shttp://www.ceagesp.com.br/cotação $\geq$. Acesso em: 25/4/2003.

CERADA M.P. Produtos e subprodutos. In: SOUZA. L.S.; FARIAS, A.R.N.; MATTOS, P.L.P.; FUKUDA, W.M.G. (Ed.). Processamento e utilizaçáo da mandioca. Cruz das Almas: Embrapa Mandioca e Fruticultura Tropical, 2005. p.15-60.

COCK, J.H.; FRANKLIN, D.; SANDOVAL, G.; JURI, P. The ideal cassava planting for maximum yield. Crop Science, v.19, p.271-279, 1979.

COCK, J.H.; WHOLEY, D.; CASAS, O.G. Effect of spacing on cassava (Manihot esculenta). Experimental Agriculture, v.13, p.289299, 1977.

CONCEIÇÃO, A. J. A mandioca. São Paulo: Nobel, 1981. 382p.

ENYI, B.A.C. Growth rates of three cassava varieties (Manihot esculenta Crantz) under varying population densities. Journal of Agricultural Science, v.81, p.15-28, 1973.

ENYI, B.A.C. The effects of spacing on growth, development and yield on single and multi-shot plants of cassava (Manihot esculenta Crantz) II: physiological factors. East African Agricultural and Forestry Journal, v.38, p.27-34, 1972.

FUKUDA, W.M.G.; FUKUDA, C.; DIAS, M.C.; XAVIER, J.J.B.N.; FIALHO, J.F. Variedades. In: SOUZA. L.S. Aspectos socioeconômicos e agronômicos da mandioca. Cruz das Almas: Embrapa Mandioca e Fruticultura Tropical, 2006. p. 433-454.

HOWELER, R.H. Cassava mineral nutrition and utilization. In: Hillocks, R. J.; Thresh, J. M.; Bellotti, A.C. (Ed.). Cassava: Biology, Production and Utilization. Wallingford NY: CABI Publishing, 2002. p.115-147.

HUNT, L.A.; WHOLEY, D.W.; COCK, J.H. Growth physiology of cassava. Field Crop Abstracts, v.30, p.77-91, 1977.

HYAMS, D. Curvexpert 1.3: a comprehensive curve fitting system for windows [softwere]. 1.34. Starkville: 1995-1997. Disponível em: < http://curveexpert.webhop.biz/z. Acesso em: 3 jul. 2003.

LORENZI, J. O. Mandioca. Campinas: CATI, 2003. 110 p. (Boletim técnico, n. 245)

LORENZI, J.O.; VALLE, T.L.; MONTEIRO, D.A.; PERESSIN, V.A.; KANTHACK, R.A.D. Variedades de mandioca para o estado de São Paulo. Campinas: Instituto Agronômico - IAC, 1996. 23p. (Boletim técnico, 162)

LORENZI, J.O. Variação na qualidade culinária das raízes de mandioca. Bragantia, v.53, p.237-245, 1994.

LORENZI, J.O.; MONTEIRO, D.A.; MIRANDA FILHO, H; RAIJ, B. van. Raízes e tubérculos. In: RAIJ, B.van; CANTARELLA, H.; QUAGGIO, J.A.; FURLANI, A.M.C. (Ed.). Recomendaçóes de adubação e calagem para o Estado de São Paulo. 2.ed. Campinas: Instituto Agronômico/Fundação IAC, 1996. P. 221-229. (Boletim técnico, n. 100)

LORENZI, J.O; VALLE, T.L. IAC 576 - A variedade de mandioca de mesa mais cultivada no Estado de São Paulo. Campinas: Instituto Agronômico, 2002. (Fôlder)

MAHUNGU, N.M. Selection for improved root quality in cassava. In: HERSHEY, C.H. (Ed). Cassava breeding: a multidisciplinary review. 1987, Cali. Proceedings... Cali: CIAT, 1987. p. 89-103, 1987.

MATTOS, P.L.P. Implantação da cultura. In: SOUZA. L.S. Aspectos socioeconômicos e agronômicos da mandioca. Cruz das Almas: Embrapa Mandioca e Fruticultura Tropical, 2006. p. 492-517.

MONDARDO, E.; DIETRICH, R.C.; LAVINA, M.L. Efeito da densidade de plantio da mandioca na produção de raízes em solo Araranguá. Agropecuária Catarinense, v.8, p.45-47, 1995.

NORMANHA, E.S.; PEREIRA A.S. Aspectos agronômicos da cultura da mandioca. Bragantia, v.10, p.179-202. 1950.

NORMANHA, E.S.; PEREIRA, A.S. Instruçōes Práticas: cultura da mandioca. O Agronômico, v.4, p.4-5, 1952.

OLIVEIRA, E.A.M; CÂMARA, G.M.S.; NOGUEIRA, M.C.S; CINTRA, H.S. Efeito do espaçamento entre plantas e da arquitetura varietal no comportamento vegetativo e produtivo da mandioca. Scientia Agricola, v.55, p.269-275, 1998.

PEREIRA, A.S.; LORENZI, J.O.; VALLE, T.L. Avaliação do tempo de cozimento e padrão da massa cozida em mandiocas de mesa. Revista Brasileira de Mandioca, v.4, p.27-32. 1985.

PERESSIN, V.A. Manejo integrado de plantas daninhas na cultura da mandioca. Campinas: Instituto Agronômico, 2010. 54p.

TAKAHASHI, M.; GUERINI, V.L. Espaçamento para a cultura da mandioca. Brazilian Archives of Biology and Technology, v.14, p. 489-494, 1998.

TÁVORA, FJ.A.F.; QUEIROZ, G.M.; PINHO, J.L.N.; MELO, F.I.O. Comportamento de cultivares de mandioca com diferentes características foliares submetidas a diversas densidades populacionais. Pesquisa Agropecuária Brasileira, v.17, p.417-431, 1982.

WILLIAMS, C.N. Growth and productivity of tapioca (Manihot utilissima): III. crop ratio, spacing and yield. Experimental Agriculture, v.8, p.15-23, 1972.

WILLIAMS, C.N. Growth and productivity of tapioca (Manihot utilissima): IV. Development and yield of tubers. Experimental Agriculture, v.10, p.9-16, 1974. 